\title{
Is possible to train health professionals in prevention of high-risk pathogens like the Ebola by using the mobile phone?
}

\section{Introduction}

Exposure to biological agents is the most common and most prevalent risk among health professionals during procedures involving direct contact with bodily fluids. The highest risk of contagion is presented for blood-borne pathogens, (Fukuda and Yamanaka, 2016), more than 30, which are mostly produced by cuts and punctures (Bergamini M, et al. 2009; Merino-de la Hoz, et al. 2010; European Parliament, 2016). Moreover, the recent movement of people and objects has provided a new possibility to spread virus and bacteria that were not originally from the area such as the emergency with the Ebola virus or the multiresistant bacteria (Mendes de Almeida, et al. 2015). In fact, the Ebola virus continues causing sporicidal active epidemics provoking numerous crisis around the world.

After parenteral exposure with a contaminated object, such as a needle with Human Immunodeficiency Virus (HIV) or another pathogen, the risk of standard infection ranges from $0.3 \%$ to $1.8 \%$; however, it can be up to $30 \%$ in susceptible individuals (Tatem, et al. 2006).

Of the biological accidents produced, needle pricks are those that present more frequently, and many of them originate after the use of biosecurity devices or during their elimination. In the United States alone, an estimated 380,000 needle pricks are reported annually in hospitals, (Sagoe-Moses, et al. 2001; Kim, et al. 1999). According to the Centers for Disease Control and Prevention (CDC), it is estimated that approximately 600,000 to $10,000,000$ occur annually; however, only one-third of these are reported, (Orozco, 2013).

From previous published studies, it is observed that nursing professionals are particularly susceptible to needle pricks, with this being the group with the highest incidence of biological accidents, (Dulon, et al. 2017).

There are numerous factors that may contribute to the possibility of a biological accident, such as lack of experience, skills, or knowledge in handling materials; anxiety; inadequate working conditions, mental fatigue, or exhaustion; and lack of awareness towards oneself or other professionals, (Cheung, et al. 2012; Yao, et al. 2010; Petrucci, et al. 2009; Tarantola, et al. 2003; Souza-Bourges, et al. 2014; Cavalcante, et al. 2013). According to Olivera and Paiva, in the face of emergencies, health professionals have a higher incidence of biological accidents and a higher prevalence in the absence of the use of standard precautionary measures.

The cost of the effects of a biological accident is high; thus, it is necessary to incorporate an effective intervention to reduce the incidence of such accidents. This intervention, according to numerous studies, should focus on information and the training of professionals or future professionals on standard precautionary measures, (Fisman, et al. 2002; Barndi, et al. 1998; Whitby, et al. 2008; Van der Molen, 2011).

The great progress made by information and communication technologies (ICTs) in recent decades has enabled the growth of new avenues of research applied to training in the health field, (Talas, et al. 2009), with many focusing on various multimedia tools, such as games, simulations, and videos, (Boada, et al. 2015; Strickland, et al. 2016). 
Currently, the use of ICTs goes beyond the transmission of information, extending their possible uses to self-learning, human behavioural transformation, the exchange of information between different professionals, and even emotional support between similar groups (e-learning), (Murray, et al. 2005; Viera de Lima Galvao, et al. 2016). The research results, mainly developed in countries such as Canada and the United States, (Boada, et al. 2015), show a wide variety of pedagogical tools that are accessible from any electronic device such as computers, mobile phones, and tablets, (Schmucker, et al. 2014; Garret and Jackson, 2006).

Learning based on e-learning and u-learning, being everywhere, allows easy access anywhere, (Strickland, et al. 2016); in addition, the design of games or simulations, included in web platforms, enables the teaching to be more dynamic while maintaining the constant attention of the users, (De-Marcos, et al. 2015).

Many nursing professionals use personal mobile phones to obtain information and to communicate with the rest of the health team, (Roberts Batista and Lin, 2016) with this objective of performing their health work, that have a greater probability of improving their clinical skills, (Mobasheri, et al. 2015).

Also, most web platforms or mobile apps are only focused on communication between health care professionals and patients with chronic diseases or groups of at-risk populations such as high-risk pregnancies, (Murray, et al. 2005; Viera de Limar, et al. 2016; Mobasheri, et al. 2015). Nevertheless, there has not been developed or implemented neither a mobile application nor a platform of any kind which purpose might be to provide information and guidance about biological risk to health professionals.

Thus, a mobile web application was developed in this research to prepare health professionals facing different scenarios of immediate risk that can arise in health care. With this application it is expected to contribute to the appropriate decision-making in real time, without placing at risk the health of the people served or that of the professionals.

\section{Materials and methods}

\subsection{Study structure}

The study has been divided into three phases:

In the first phase, a cross-sectional study was conducted. It focuses on analysing the incidence of biological accidents in future nursing professionals (students in their final year), evaluating the variables that intervene in the prevalence of data such as the degree of knowledge of biosecurity measures and their compliance. Additionally, it attempts to determine all the factors that can cause the increase in accidents, to be able to control and to diminish them.

The second phase focused on the design of the Mobile Web Application Health for information and the training of professionals in the health sector: "Immediate Information for health professionals" (PSAM) (http://www.uco.es/psam/rpsindice.php). The main purpose of developing and designing this web is to obtain a resourceful application that can provide any type of information to professionals deleting their doubts and providing information in several matters such as biological accidents or how to eliminate the biological waste.

The third phase was a cross-sectional study focused on the evaluation of the technology developed by using the CIPP method, (the Context, Input, Process and Products method), oriented to objectives, testing, and experimental design. According to the CIPP method, the evaluation should consider four issues, namely context, input, process and product. It was used a survey to carry out a double study orientated to the professionals and students in formation. The evaluation has been based on the CIPP method to accomplish this task; several questionnaires based on a recent work have been used, following the methodology proposed by Stufflebeam in 2003. Before completing the survey, the different groups were given a short session on how to use the platform as a help tool. 


\subsection{Technology developed}

It has the characteristic of being freely and wherever accessible, which allows it to be used by any professional and anywhere. It is also available the English and Spanish version of the different themes depending on the user's language.

This application includes several functionalities: 1. multi-platform mobile web application: PC, tablet, or phone; 2. functionality in any operating system such as Windows, Linux, Android, and iOS; 3. Being operative from any browser: Internet Explorer, Firefox, Chrome, Safari, etc.; 4. Being simple and easy to navigate; 5 . fast data processing and error detection in data entry; 6 . simplicity in the design of menus; and 7. adaptive automatic resizing of the screen according to its size.

The platform was implemented using the following development tools: as a programming language, PHP version 5.2.17 has been used; as text editor for coding, the Aptana Studio 3 software version 3.6.1; as fundamental technologies for the creation of HTML web pages for the base structure and CSS for style and design; as interpreted programming language, JavaScript, using JavaScript library to interact with HTML documents and jQuery version 1.7.1; for mobile devices, as an optimized framework, JQuery Mobile version 1.1.0 was used, for management of library files, XLSX, and PHPExcel version 1.8.0.

The database server has MySQL version 5.0.77 installed, and the web server is Apache version 2.2.3. Additionally, it has been verified that the application runs correctly in all web browsers, i.e., Internet Explorer, Mozilla Firefox, and Google Chrome in Windows, and can be used on any electronic device, including all mobile devices that use Windows, Android, and iOS (Mac) operating systems.

It has been designed with two levels of users, managers and user health professionals, respectively.

Manager. To keep the web permanently updated, it must be dynamic and easily managed (http://www.uco.es/psam/rpsgestion.php). To that end, it has been equipped with a management tool that allows continuous updating by the professional expert in charge and is accessed through a username and management password. The manager level has four design applications associated and requires a restricted login:

1. The design of questionnaires that includes the introduction of questions, multiple answers, and the inclusion of photographs and videos.

2. Design of tutorials. This tutorial manager allows the introduction of written information, photos, and explanatory videos, with fast hyperlinked words (Figure 1).

3. The creation of image galleries with subtitles, in which both methods and materials can be introduced to prevent and respond to situations of danger.

User. This has two possible options with free access:

1. "Thematic search" is a search engine that allows the localization of the topics contained in the search pattern word, allowing one to respond to "what I need to know right now"; this option is recommended in situations of danger or work.

2. "Thematic index", which gives immediate responses to risk situations created in the work environment. This folder has quick access to tutorials that contain information (Figure 2), multimedia tools (Figure 3), videos, and images that make it possible to respond to "what information do I need or need to know".

\subsection{Data collection}

In the first phase, the study focused on students in their last year of the nursing programme at the University of Cordoba $(\mathrm{N}=33)$, who voluntarily responded to the survey via Google after completing their degree ( $\mathrm{N}$ $=23$ ). 
The independent variables of the study are: the degree of knowledge, practices performed, sex, age, and previous studies and practices performed; and the dependent variable is having suffered biological accidents. These variables were obtained through a questionnaire, without access to personal data, guaranteeing at all the times the compliance with the Data Protection Law.

The study was implemented through a Google questionnaire of our own design, taking as reference the works of Merino-de la Hoz, et al. in 2010 and Orozco, et al. in 2013.

The questionnaire is composed of 48 questions. The issues are grouped into five major blocks, which correspond to the following percentages: basic knowledge, $22.91 \%$ of the total (handwashing, use of personal protective equipment (PPE), etc.); specific knowledge, $8.33 \%$ (the value of seroconversion of hepatitis B and C and AIDS); actions during practices, 16.67\% (adherence to practice protocols and standard protection measures); the incidence of biological accidents, $25 \%$ (frequency of biological accidents, speed during procedures, amount of work); and, finally, the degree of satisfaction and information of interest, $27 \%$.

In the third phase, the data was collected means of a questionnaire for expert professionals $(N=7)$, with more than 30 years of experience, or nursing specialists. Moreover, a study of the acceptability and opinion, (Schmucker, et al. 2014), of future health technicians was conducted $(\mathrm{N}=26)$.

\subsection{Samples Size Calculation}

The number of students was determined from an expected proportion of $98 \%$, a precision of $5 \%$ and a confidence level of $95 \%$.

The sample size for expert professionals and future health technicians was calculated from a standard deviation of 4 , a precision of $3 \%$ and a confidence level of $95 \%$

\subsection{Statistical Analysis}

The statistical analysis was conducted using the SPSS version 15 statistical package and represented graphically. The incidence of the biological accidents with respect to the degree of basic and specific knowledge was calculated, in addition to biosecurity measures and their compliance. The study of the relationship between the knowledge of standard protection measures and the degree of satisfaction of the quality of the received training was performed. The hypothesis test used was the chi-squared test.

The results from the third phase were stored for statistical analysis in a datasheet. A descriptive study was conducted for the qualitative variables and the mean, the standard deviation, the standard error, and the coefficient of variation for the quantitative variables used to estimate the study variables.

\section{Results}

\subsection{First phase}

The results are centred in a group of fourth-year nursing students with a mean age of 23 and half years. Most of these students had a previous technical degree (54.44\%) related to health in its entirety, meanwhile the most of the rest of these students where from high school (40.91\%)

In addition, the prevalence of basic knowledge and specific prevention measures (Table 1) on biological accidents and biological agents was assessed. The results show that $79.55 \%$ answered correctly on the basic knowledge questions; however, for the specific knowledge questions, half of the sample (51.82\%) answered correctly, with a confidence interval (CI) from $78.75 \%$ to $80.35 \%$.

The incidence of biological accidents at the end of the degree, prior to working in the National Health System, is $23 \%$. In addition, questions on biological accidents are evaluated, such as how the accident 
occurred, the body area where the accident occurred, whether the student used PPE when it occurred, possible causes of the accident, and the degree year in which the accident was produced (Figure 4).

The results reflect the following: the most common accidents are pricks $(60 \%)$; the body area where accidents occur are the fingers (80\%); only $60 \%$ of students had used PPE when the accident occurred; the possible cause as assessed by students is the amount of work (40\%); and, finally, the year in which there was a higher incidence of biological accidents was the third year.

The chi-squared independence test concerns the two qualitative variables, "route to the nursing degree" and "have you ever had a biological accident during your clinical practice" (Table 2). The results of the test (Pearson's chi-squared 6.8157 and p-value 0.033; Fisher's test p-value 0.028) reflect that the proposed null hypothesis, that is, that there is no dependence of the two variables, is rejected and that the alternative hypothesis, that is, that there is a dependency between both variables, is accepted.

\subsection{Second phase}

The results obtained from the interviews with health experts and technical students in the health sciences on the PSAM platform have been divided into thematic search evaluation, general opinion of the application, information contained in the themes, the rules that are in the platform, the usability of the platform, and multimedia content.

The results of the survey of the experts (Table 3) show that the overall evaluation of the platform was on average 4.0 out of 5 , with this value being defined as good by the health experts, which implies that the platform developed has a great potential in order to inform and train the health professionals. However, when studying the remaining questions about the platform and the information that it contains, the averages obtained are lower on the information and content of the platform (3.93/5 in information, 3.62/5 in rules, and 3.98/5 in multimedia content), although usability and thematic search (4/5 and 4.25/5) are better valued.

In relation to the evaluation of the PSAM platform performed by the students (Table 4), this shows how the overall opinion and thematic search (3.87/5 and 3.91/5) are lower than the results of the professional health experts, regarding it as being between "good" and "acceptable". Nevertheless, the results show that the information of the themes is valued, with a score of $4 / 5$, in other words, good; however, the multimedia content (3.65/5) and the rules (3/5) are the worst evaluated.

Finally, we asked the two samples of students and professionals what could be improved on the platform for their use (Figure 5). The professionals focused on improving the content of the platform, whereas the students focused on new technologies and social networks to improve communication.

\section{Discussion}

This study focused on mainly the creation of a mobile web app, in order to decrease the incidence of biological accidents by a rapid response to specific problems, and its double evaluation by professionals and future health technicians; and secondly, the analysis of the incidence of biological accidents and the different variables that influence it.

The results obtained show that the average of the knowledge of the standard precautions of the respondents was $79.54 \%$, higher than the average obtained in previous studies focused on students (Bergamini, et al. 2009; Merino de la Hoz, et al. 2010). However, this average is lower than that obtained in previous international studies focused on nursing professionals from various services such as emergencies (83.2\%), (Oliveira and Paiva, 2013; Sax, et al. 2005).

The response to the incidence of biological accidents shows that $23 \%$ of the respondents have suffered some type of accident. This reflects a higher incidence of students regarding the incidence of biological accidents among emergency nursing professionals (20.6\%) in countries such as Brazil, (Oliveira and Paiva, 2013), even though this group of professionals must act with extreme speed. However, there are studies that demonstrate the variability of incidence of these accidents; thus, Oliveira and Paiva in 2013, and 
Memish, et al. in 2002, show a frequency of accidents among health professionals ranging from $18.4 \%$ to $100 \%$, and the study by Costigliola, et al. in 2012, shows that, the incidence varies between European countries, from $15.4 \%$ in the UK to $55 \%$ in Greece.

Regarding to the results of this study, these show that $60 \%$ of the respondents were using PPE at the time of the accident, which is lower than the results of previous studies that estimate that nursing professionals who had an accident and were using PPE varies between 61\% and 68\%, (Dulon, et al. 2017; Fisman, et al. 2002).

From the analysis of the frequency of final-year students on their perception of the cause of biological accidents, it is observed that $20 \%$ believe that they are due to a lack of knowledge, $40 \%$ because of the amount of work, $20 \%$ due to a lack of attention, $20 \%$ because of the use of measures that involve a risk factor, for example, encapsulation, and, finally, $20 \%$ due to other reasons, such as problems with or misuse of safety equipment, that is, practice error. These results compared to previous student-centred studies, are somewhat lower, (Bergamini, et al. 2009; Merino de la Hoz, et al. 2010), although compared to the results from professional-centred studies, a higher frequency is observed (Oliveira and Paiva, 2013). In addition, the results with respect to the lack of precaution show that only $20 \%$ of respondents consider that this was the cause of the accident, whereas in studies on professionals, it is considered that the lack of precaution is the major cause of accidents, between 49\% and 66\%, (Dulon, et al. 2017; Öztürk Engin, et al. 2014).

There is a significant correlation between previous knowledge and the incidence of biological accidents. Thus, students coming from a previous health technical degree programme who have greater knowledge of standard precautionary measures have a greater probability of suffering a biological accident than those coming from high school, perhaps due to a lack of caution or overconfidence, among other factors. This situation coincides with what is described by health professionals from different countries and professions, (Oliveira and Paiva, 2013). Accordingly, it follows that it is necessary to increase training through training sessions that must be performed during school hours, particularly in the first years of the degree programme, and to have a thorough impact on advanced courses and health professionals.

The results show how the platform has been evaluated by students and experts at approximately 4 out of 5, defining it as "good". However, the results show how students value the content and platform worse, from 3.0 to 4 , whereas experts value it better, from 3.62 to 4.25 . These values coincide with previous studies focused on patients' platforms, in which satisfactory results regarding the opinion of users were obtained, (Murray, et al. 2005; Viera de Lima, et al. 2016; Schmucker, et al. 2014).

Finally, it is observed that the professionals focus on the content of the platform, that is, the available information, which, according to them, should be concise and complete. Students, on the other hand, focus on multimedia content and social networks, (Dulon, et al. 2017; Hayes, et al. 2015), attaching greater importance to peer communication. These results corroborate others previously obtained for patient-centred health tools, (Di Lucca and Fasolino, 2006; Holden and Karsh, 2010).

\section{Conclusions}

The importance of information and training on biological accidents and prevention measures has been demonstrated, in addition to the influence of psychosocial aspects on this incidence.

The importance of this study resides in an upgradeable platform being used in everywhere and in any electronic device available on the market by any user and being the unique platform offered to provide knowledge of actions under biological risk. This application contributes to the appropriate decision-making in real time, without placing at risk the health of the people served or that of the professionals. In addition, this application can be updated at any time incorporating any type of current information on health.

This platform has been valued as satisfactory by potential users, students and professionals, although areas for improvement have been observed for future research. 
Future research should examine the association of the platform use with the decrease of biological accidents and improvement of prevention knowledge among health professionals.

\section{Limitations and Future research}

There are some limitations in this study, which offer suggestions and implications for future research.

The website developed is a first simplistic and ubiquitous version focused on helping healthcare professionals in situations of immediate risk. In addition, in order to evaluate the application, a satisfaction survey was carried out to health sciences students and health professionals. It was asked to the participants to freely answer the survey about their opinion referring to the web and how they perceived information included in software. Although, the surveys provide some information about the different samples included, the sample obtained has not been significance to analyses further questions related with their opinion. Moreover, the software validation has focused on the videos and images related professional healthcare activities.

In future research will be the inclusion of a multiple scenarios of possible expose to high-risk pathogens, level four and three, in a virtual reality using 3D technology. Additionally, it will be included the option of selecting avatars whose characteristics will be different and because of it will different routes to select the actions to take in order to avoid the exposure and the decisions post-contamination. This reality will be developed to be used in a mobile phone because of the easy accessibility, instead of being supported by the computer and the virtual glasses that cannot be freely transported.

\section{Acknowledgements}

The data analysis and manuscript preparation were supported by the framework of UCO Social Innova Project from the institution of OTRI of the University of Cordoba, Spain. The content is responsibility of the authors and does not necessarily represent the official views of the OTRI.

\section{References.}

Barndi S, Benatti MCC, Alexandre NMC. (1998). Ocorrência de accidente do trabalho por material perfurocortante entre trabalhadores de enfermagem de un hospital universitário da cidade de Campinas, Estado de Sao Paulo. Revista da Escola de Enfermagem da USP, 32 (2), 12-33.

Bergamini M, Gucchi A ,Stefanati A, Cavallaro A, Gabutti G. (June 2009). Knowledge of preventive measures against occupational risks and spread of healthcare-associated infections among nursing students. An epidemiological prevalence study from Ferrara, Italy. Journal of Preventive Medicine and Hygiene, , 50(2), 96-101.

Boada I, Rodriguez-Benitez A, Garcia-Gonzalez JM, Olivet J, Carreras V, Sbert M. (November 2015) Using a serious game to complete CPR instruction in a nurse faculty. Computer methods and programs in biomedicine, 122 (2), 282-291.

Cavalcante CAA, Cavalcante EFO, Macêdo MLAF, Cavalcante ES, Medeiros SM. (2013). Acidentes com material biológico em trabalhadores. Revista da Rede de Enfermagem do Nordeste, 14 (5), 971979.

Cheung K, Siu Yin Ching S ,Ka Pik Chang K, Ho SC (2012) Prevalence of and risk factors for needlestick and sharps injuries among students in Hong Kong. American Journal of Infection Control, 40 (10), 997-1001.

Costigliola V, Frid A, Letondeur C, Strauss K. (2012) Needlestick injuries in European nurses in diabetes. Diabetes \& Metabolism. 38, 9-14.

de-Marcos L, Garcia-Lopez E, Garcia-Cabot A. (December 2015). On the effectiveness of game-like and social approaches in learning: Comparing Educational gaming, gamification \& social networking. 
Computers \& Education, 29 (95), 99-113.

Di Lucca GA , Fasolino AR. (December 2006) Testing web-based applications: the state of the art and future trends. Information and Software Technology, 48 (12), 1172-1186.

Dulon M, Lisiak B, Wendeler D, Nienhaus A, (2017) Causes of needlestick injuries in three healthcare settings: analysis of accident notifications registered six months after the implementation of EU Directive 2010/32/EU in Germany. Journal of Hospital Infection, 95(3), 306-311.

Murray E, Burns J, See Tai S, Lai R, Nazareth I. (2005) Interactive Health Communication Applications for people with chronic disease. Cochrane Database of Systematic Reviews, 4. Art. No.: CD004274. DOI: 10.1002/14651858.CD004274.pub4.

European Parliament, Preventing needle-stick injuries in the health sector, 11 th February 2010, http://www.europarl.europa.eu/sides/getDoc.do?pubRef=-//EP//TEXT+IM-

PRESS+20100210IPR68824+0+DOC+XML+V0//EN (accessed 4 Sep 2016).

Fisman DN, Mittleman MA, Sorock GS, Harris AD. (2002) Willingness to pay to avoid sharps-related injuries: a study in injured health care workers. American journal of infection control, 30 (5), 283-287.

Fukuda H, Yamanaka N. (2016), Reducing needlestick injuries through safety-engineered devices: results of a Japanese multi-center study, Journal of Hospital Infection. 92 (2), 147-153.

Garrett BM, Jackson C. (December 2006) A mobile clinical e-portfolio for nursing and medical students, using wireless personal digital assistants (PDAs), Nurse Education Today, 26(8), 647-54.

Hayes M, Van Stolk-Cooke K., Muench, F. (2015) Understanding Facebook use and the psychological affects of use across generations, Computers in Human Behavior, 49, 507-511.

Holden RJ, Karsh BT. (2010) The technology acceptance model: its past and its future in health care. Journal of biomedical informatics; 43(1), 159-172.

Kim LE, Evanoff BA, Parks RL, Jeffe DB, Mutha S, Haase C, Fraser VJ. (1999) Compliance with universal precautions among emergency department personnel: implications for prevention programs, American Journal of Infection Control, 27 (5), 453-455.

Memish ZA, Almuneef M, Dillon J. Epidemiology of needlestick and sharps injuries in a tertiary care center in Sadi Arabia. Infect Cntrol Hosp Epidemiol. 2002;30(4):234-41.

Mendes de Almeida MC, Marin da Silvia SR, Reis RK, et al. Clinical treatment adherence of health care workers and students exposed to potentially infectious biological material. Rev esc enferm. 2015; 49(2): 261-6.

Merino-de la Hoz F ,Durá-Ros MJ ,Rodríguez-Martin E ,et al. Conocimiento y cumplimiento de las medidas de bioseguridad y accidentes biológicos de los estudiantes de enfermería en las prácticas clínicas. ENFERMERÍA CLÍNICA. 2010 Mayo; 20 (3): 179-85.

Mobasheri MH,King D, Johnston M, et al.The ownership and clinical use of smartphones by doctors and nurses in the UK: a multicenter survey study . BMJ Innov 2015;00:1-8.

Oliveira AC, Paiva MHRS. Analysis of occupational accidents with biological material among professionals in pre-hospital services. Rev Latino Am Enfermagem. 2013;21(1):309-15.

Orozco MM. Accidentalidad por riesgo biológico en los estudiantes de enfermería de la universidad de ciencias aplicadas y ambientales U.D.C.A., Bogotá, Colombia. Journal of school of Nursing. 2013 ; 16(1): 27-33. 
Öztürk Engin D, İnan A. , Ceran N , Zeynel Abiddin Demir , Özgür Dağli , Emin Karagül, Seyfi Özyürek (2014) Occupational exposure among healthcare workers: a teaching hospital sample. Journal of Microbiology and Infectious Diseases, 4 (2): 64-68

Petrucci C, Alvaro R, Cicolini G, Cerone MP, Lancia L. (2009) Percutaneous and mucocutaneous exposures in nursing students: an Italian observational study, Journal of nursing scholarship 41(4), $337-343$.

Roberts Bautista J, Lin T.C. Sociotechnical analysis of nurses' use of personal mobile phones at work. InternationalInt J Med Inform. 2016 Nov;95:71-80.

Sagoe-Moses C, Pearson RD, Perry J, et al. Risks to health care workers in developing countries. N Engl J Med 2001;345:538-41.

Sax H, Perneger T, Hugonnet S, et al. Knowledge of standard isolation precautions in a large teaching Hospital. Infect Cotrol Hosp Epidemiol. 2005;36(3):298-304.

Schmucker, M. ; Heid, J. ,Haag, M. Development of an accommodative smartphone app for medical guidelines in pediatric emergencies. Health Technol Inform. 2014 198:87-92.

Souza-Bourges FR, Ribeiro LA ,Olivera LC . ( March-April 2014) Occupational exposure to body fluids and behaviors regarding their prevention and post-exposure among medical and nursing students at a Brazilian public university, Revista do Instituto de Medicina Tropical de São Paulo. 56 (2), $157-63$.

Strickland HP, Kaylor SK . (2016) Bringing your a-game: Educational gaming for students success. Nurse Education Today. 40, 101-3.

Stufflebeam LD. (2003) The CIPP Model for Evaluation. Kluwer International Handbooks of Education, Springer Netherlands. 31-62.

Talas MS. (May 2009) Occupational exposure to blood and body fluids among Turkish nursing students during clinical training: frequency of need lipstick/sharp injuries and hepatitis B immunization. Journal of clinical nursing, 18 (10), 1394-1403.

Tarantola A, Golliot F, Astagneu P, Fleury L, Brücker G, Bouvet E. (2003) Occupational blood and body fluids exposure in health care workers: four-year surveillance from the northern France network. American journal of infection control, 31(6), 357-363.

Tatem AJ, Rogers DJ., and Hay SI. Global Transport Networks and Infectious Disease Spread. Advances in parasitology. 2006; 62: 293-343.

Van der Molen HF, Zwinderman KAH, Sluiter JK, Frings-Dresen H.W.M. (2011) Better effect of the use of a needle safety device in combination with an interactive workshop to prevent needle stick injuries. Safety Science, 49 (8-9), 1180 -1186

Viera de Lima,Galvão MT, Alexandre Hde O, Lima FE, Araújo TL, (August 2016) Information and communication technologies for adherence to antiretroviral treatment in adults with HIV/AIDS. International Journal of Medical Informatics.; 96, 54-6.

Whitby M, McLaws ML, Slater K. (2008) Needlestick injuries in a major teaching hospital: the worthwhile effect of hospital-wide replacement of conventional hollow-bore needles. American Journal of Infection Control, 36, 180-186.

Yao WX, Yang B ,Yao C, Bai PS, Qian YR, Huang CH, Liu M. (2010) Needlestick injuries among nursing students in China. Nurse education today, 30 (5), 435-7. 
Tables

\begin{tabular}{|l|l|c|}
\hline & Prevalence & Prevalence \\
\hline Basic Knowledge & $79.55 \%$ & $78.75 \%-80.35 \%$ \\
\hline Specific knowledge & $51.82 \%$ & $50.84 \%-52.80 \%$ \\
\hline
\end{tabular}

Table 1: Prevalence of basic and specific knowledge

\begin{tabular}{llll}
\hline & \multicolumn{4}{l}{ Have you ever had a biological accident during your practice? } \\
\hline Route to nursing & No & Yes & Total \\
High school & $40.9 \%$ & $0.0 \%$ & $40.9 \%$ \\
Technical degree & $36.4 \%$ & $18.2 \%$ & $54.5 \%$ \\
Over 25 years of age & $0.0 \%$ & $4.5 \%$ & $4.5 \%$ \\
Total & $77.3 \%$ & $22.7 \%$ & $100.0 \%$ \\
\hline Pearson's chi-squared test & df $=2$ & p-value $=0.03311$ \\
X-squared = 6.8157 & & &
\end{tabular}

Have you ever had a biological accident during your practice?

\begin{tabular}{|llll|}
\hline & No & Yes & Total \\
\hline High school & $0.0 \%$ & $40.9 \%$ & $40.9 \%$ \\
\hline Technical degree & $18.2 \%$ & $36.4 \%$ & $54.5 \%$ \\
\hline Over 25 years of age & $4.5 \%$ & $0.0 \%$ & $4.5 \%$ \\
\hline Total & $22.7 \%$ & $77.3 \%$ & $100.0 \%$ \\
\hline
\end{tabular}

$\underline{\text { Fisher's exact test for count data }}$

p-value $=\mathbf{0 . 0 2 8 3 7} \quad$ alternative hypothesis: two-sided

Table 2: Chi-squared independence test 


\begin{tabular}{|l|l|c|c|}
\hline PSAM score $(\mathrm{N}=7)$ & Mean & $\begin{array}{c}\text { SE } \\
\text { (Standard error of mean) }\end{array}$ & $\begin{array}{c}\text { CV } \\
\text { (Coefficient of variation) }\end{array}$ \\
\hline General opinion of PSAM & 4.00 & 0.20 & 0.10 \\
\hline Thematic search & 4.25 & 0.10 & 0.05 \\
\hline Topic information & 3.94 & 0.16 & 0.08 \\
\hline Rules & 3.63 & 0.24 & 0.13 \\
\hline Usability & 4.00 & 0.20 & 0.10 \\
\hline Multimedia content & 3.99 & 0.11 & 0.06 \\
\hline
\end{tabular}

Table 3: Assessment of the PSAM by health experts

\begin{tabular}{|l|c|c|c|}
\hline $\begin{array}{l}\text { PSAM assessment of } \\
\text { students }(\mathrm{N}=26)\end{array}$ & Mean & $\begin{array}{c}\text { SE (Standard error } \\
\text { of mean) }\end{array}$ & $\begin{array}{c}\text { CV } \\
\text { (Coefficient of } \\
\text { Variation) }\end{array}$ \\
\hline General opinion of PSAM & 3.87 & 0.20 & 0.25 \\
\hline Thematic search & 3.91 & 0.23 & 0.28 \\
\hline Topic information & 4.00 & 0.17 & 0.20 \\
\hline Rules & 3.00 & 0.14 & 0.23 \\
\hline Usability & 3.83 & 0.17 & 0.22 \\
\hline Multimedia content & 3.65 & 0.21 & 0.27 \\
\hline
\end{tabular}

Table 4: Assessment of the PSAM by technical students in the health sciences 


\section{Figures Caption}

Figure 1: Theme manager (a) Initial page to edition (b) Inside the page edition

Figure 2: Immediate information search

Figure 3: Multimedia resource

Figure 4: Qualitative variables related to biological accidents

Figure 5: Aspects to be improved described by experts and students 


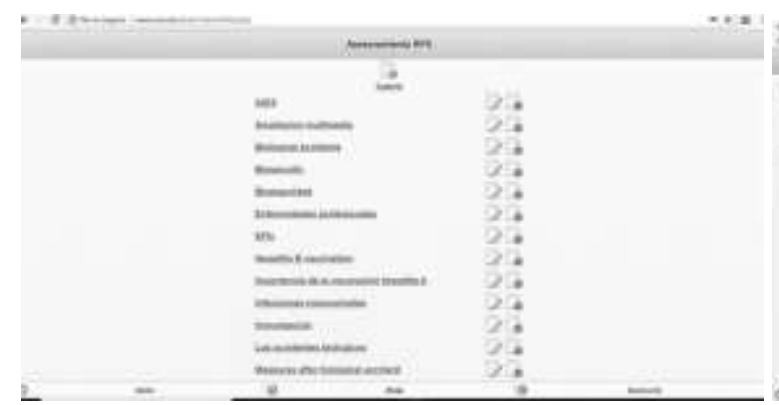

(a)

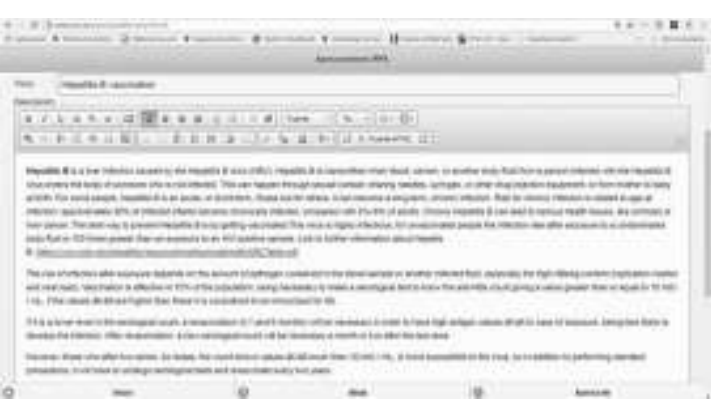

(b)

Figure 1

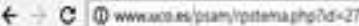

Asesoramiente RPS

\section{$\underline{\text { AIDS }}$}

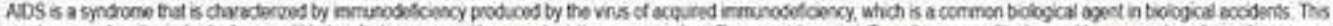

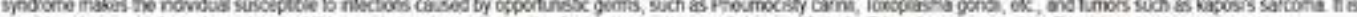

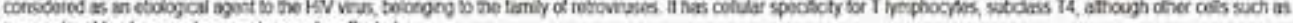
inonocyes biood maschapas, etc may be abocted

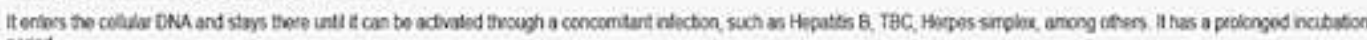
period

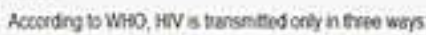

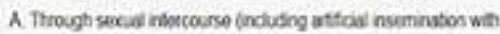

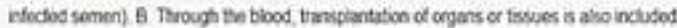

C. Fron ne inteded nother b ter ctid (pertadal tansmissoo)

Peverbon

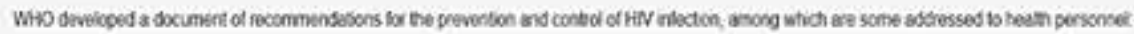

1. Hend washing wh seep and water.

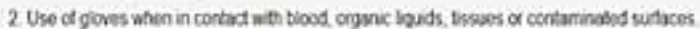

3. Porsonal protoctwe equipnent, lenses, cap, mask long smocks.

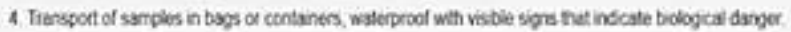

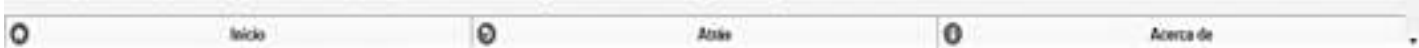

Figure 2 


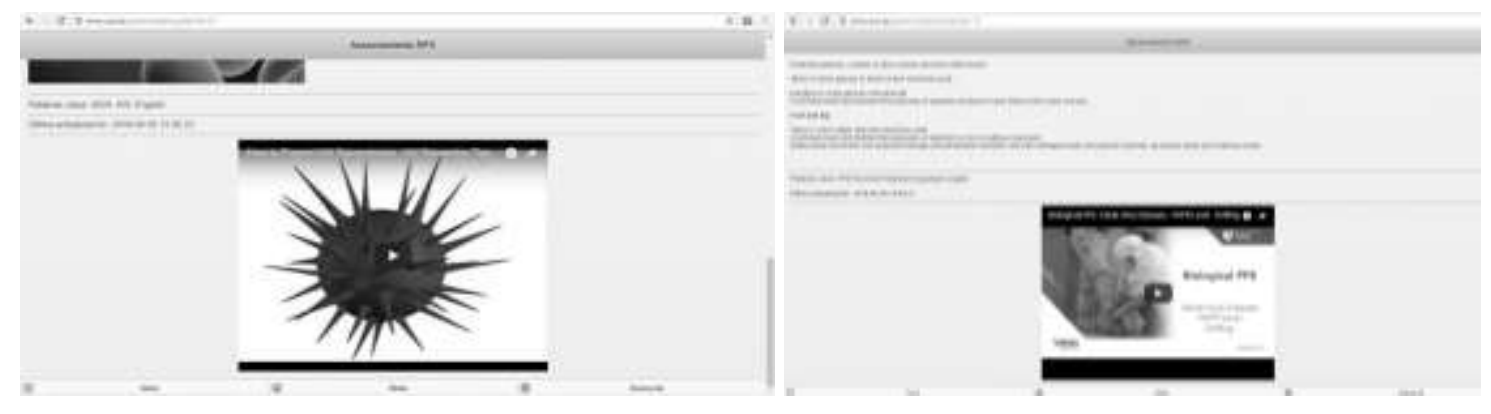

Figure 3

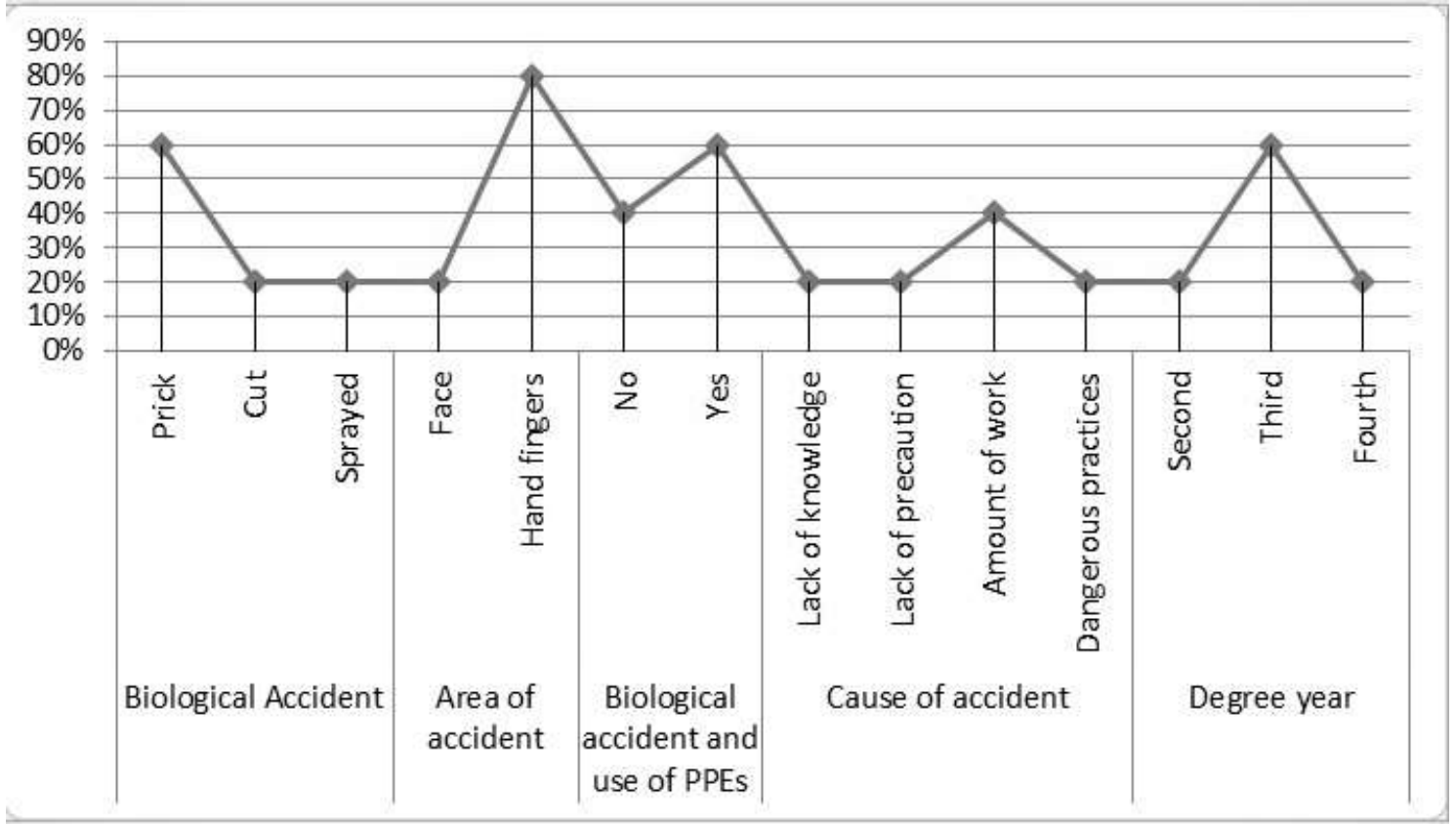

Figure 4 


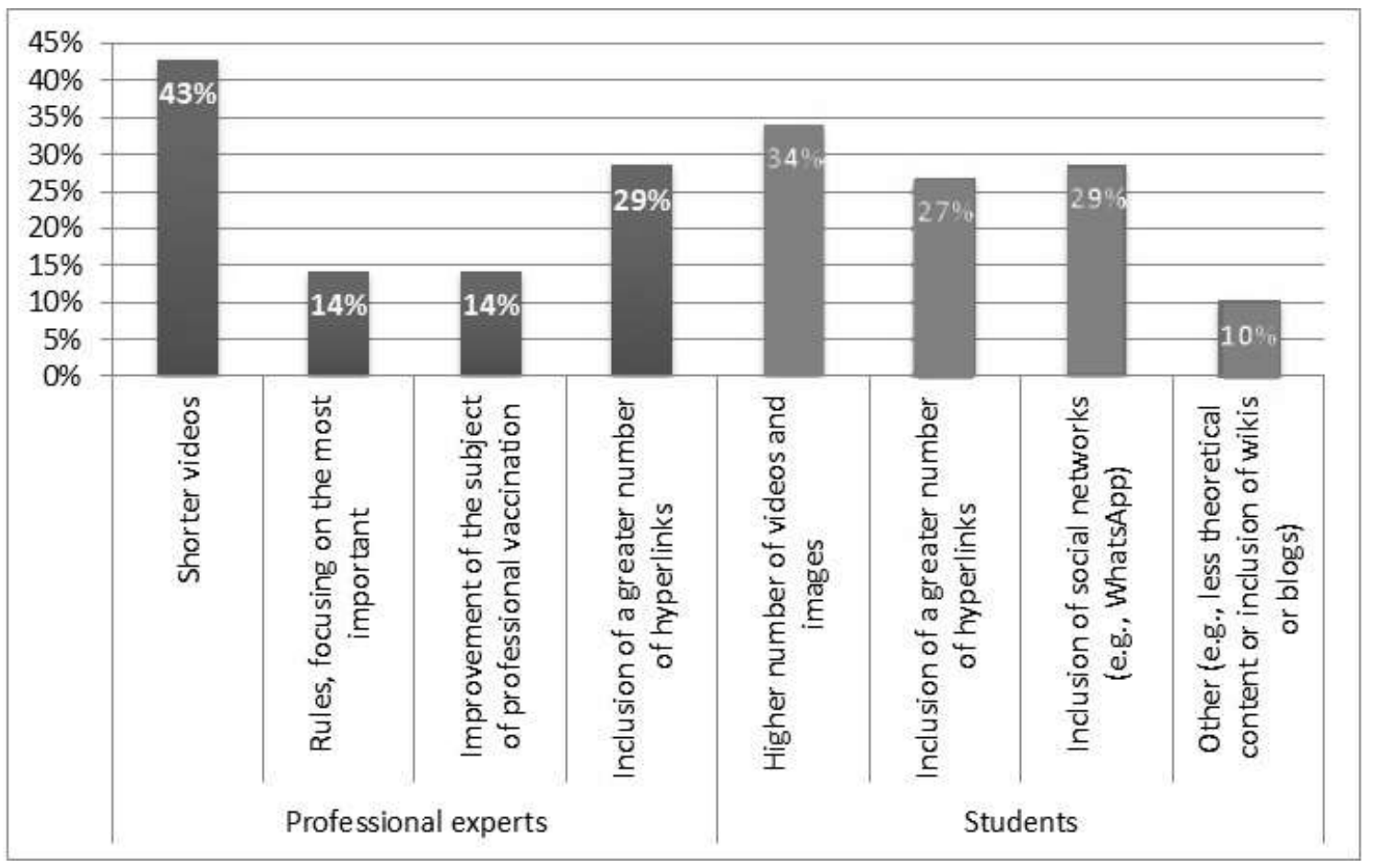

Figure 5 